\title{
Adam Smith and Three Theories of Altruism
}

\author{
Elias L. Khalil* \\ American Institute for Economic Research, \\ and Department of Economics, Vassar College
}

\section{Introduction}

During the past three decades, economists have developed theories of altruism that depart in different ways from the narrowly conceived Homo economicus model. These theories can be broadly classified into three broad approaches. The first, called here the "egoistic" perspective, can be seen as a variant of reciprocal cooperation models such as the one proposed by Axelrod (1984). It maintains that one may share his income with another to induce a reciprocal transfer in the future. The second, named the "egocentric" view, as epitomized in Becker (1976), argues that the donor's utility function includes the utility of potential recipients. That is, the donor would donate a resource if the vicarious enjoyment of watching the pleasure of others exceeds at the margin the donor's satisfaction from consuming the resource himself. The third, dubbed the "altercentric" framework ("alter" after the Latin "other"), can be surmised from the work of Mead (1934), Etzioni (1986), Frank (1988), and Simon (1990). It views the benefactor's action as stemming from a moral dictum as binding as rules of honesty.

Smith leveled direct criticisms against three theories of altruism current in his time. Amazingly, these theories are replicas of the ones just mentioned. Smith put forward an alternative based on the idea of sympathy.

* Behavioral Sciences Research Council, a division of the American Institute for Economic Research, www.brc-aier.org, and Department of Economics, Vassar College, elkhalil@vassar.edu. A longer version benefited from the comments of Gary Becker, Ulrich Witt, Robert Goldfarb, Mark Wilhelm, Timothy Crippen, John Davis, Thomas Nitsch, Roger Masters, participants of sessions at the University of Freiburg, University of Chicago, and American Economic Association meeting, anonymous referees, and especially Robert Frank. This work was made possible by a research fellowship from the Alexander von Humboldt Foundation. The usual disclaimer applies. 
Although a few modern writers have noted Smith's theory (e.g., Collard, (1978; Frank, (1988), a fewer realized its pertinence to the modern debate. Section one provides a succinct statement of Smith's theory. Section two summarizes Smith's critique of the three theories of his time. Section three identifies the modern approaches and shows how they still fail to answer Smith's critique.

\section{Back to Smith}

\subsection{The Principle of Sympathy}

Smith's theory of ethics was greatly influenced by David Hume's notion of sympathy (Mackie, (1980; Haakonssen, (1981). However, in The Theory of Moral Sentiments, Smith departed from Hume's utilitarian position, which portrays sympathy as the mechanism by which the agent calculates social welfare. For Smith, sympathy stems from instantaneous sentiments towards immediate experiences; it does not generally arise from meditated calculation of the welfare of all concerned. Smith viewed sympathy as the foundation of virtues pursued for their own sake, not for the sake of advancing social welfare. He regarded sympathy to be the foundation of beneficence (altruism), self-command (the propriety of behavior), respect and admiration, and social rank (Khalil (1990), (1996)).

Concerning benevolence, Smith stressed that sympathy expresses the genuine concern over the interests of others, in short "other-interest". This concern entails that the benefactor has to suspend his own interest. The negation of self-interest, however, does not mean that altruism stems from a principle, which is radically different from self-interest. For Smith, the motive to satisfy self-interest and other-interest stems from the same general tendency of humans to sympathize-in one case with the self and in the other with the beneficiary. That is, Smith did not view self-interest as radically different from other-interest : both are simply different instances of sympathy. We witness that man acts more often in sympathy with the self (i.e., out of self-interest) because man is obviously more familiar with the circumstance of his own self than with the circumstance of others. That is, for Smith, there is no fundamental distinction, but only a difference in degree, between one's own feelings as opposed to the feeling of others towards one's interest.

To be precise, however, Smith appears to note a difference between self-interest and the sympathy of others with one's interest. While selfinterest seems to be an "original" sensation, the sympathy of others with one's interest does not take place immediately. Rather, it is a mediated or "reflected" sympathy with the agent who is originally experiencing the benefit or pain : 
Every man, as the Stoics used to say, is first and principally recommended to his own care; and every man is certainly, in every respect, fitter and abler to take care of himself than of any other person. Every man feels his own pleasures and his own pains more sensibly than those of other people. The former are original sensations; the latter the reflected or sympathetic images of those sensation. The former may be said to be the substance, the latter the shadow (Smith (1976) p. 219).

That is, a spectator can assess a benefit or pain only through the reaction of the agent who is experiencing it. Nonetheless, this difference does not change the claim posited here that there is no fundamental distinction between self-interest and sympathy. When an agent sympathizes with someone else's feelings towards, e.g., an apple, it is a reflective sensation. Likewise, when the agent sympathizes with his own feelings towards the apple, it is also a reflective sensation: That is, both sensations involve sympathy and, hence, by definition, are reflective of original sensations. The only difference between the two cases arises from the degree of familiarity occasioned by the usual fact that the agent is more familiar with his own feelings than with the feelings of the other. (To note, however, this is not always trueas in the case when an agent is more attuned to the feelings of others than to his own.)

For altruism, the degree of familiarity is crucialand agents act most of the time in a self-interested manner only because they are familiar mostly with their own original sensations than with the original sensations of others. Obviously, there is a stronger motive to help a stranded person if the person happens to be a close acquaintance rather than, ceteris paribus, a distant associate. And man is more motivated to help, after himself, the ones who live in the same house with him than "the greater part of other people" :

After himself, the members of his own family, those who usually live in the same house with him, his parents, his children, his brothers and sisters, are naturally the objects of his warmest affections. They are naturally and usually the persons upon whose happiness or misery his conduct must have the greatest influence. He is more habituated to sympathize with them. $\mathrm{He}$ knows better how every thing is likely to affect them, and his sympathy with them is more precise and determinate, than it can be with the greater part of other people. It approaches nearer, in short, to what he feels for himself (Smith (1976) p. 219).

Social proximity, in addition, illuminates for Smith why the agent feels less affection towards the children of his cousins than towards the children of his sisters and brothers :

The children of cousins, being still less connected [than "the children of brothers and sisters"], are of still less importance to one another; and the affection gradually diminishes as the relation grows more and more remote (Smith (1976) p. 220).

Social remoteness also explains for Smith why the parent-child affection is weaker if the child was separated from the father from its infancy: 
A father apt to be less attached to a child, who, by some accident, has been separated from him in its infancy, and who does not return to him till it is grown up to manhood. The father is apt to feel less paternal tenderness for the child; the child, less filial reverence for the father. Brothers and sisters, when they have been educated in distant countries, are apt to feel a similar diminution of affection (Smith (1976) pp. 220-221).

Smith's notion of social proximity is conceptually analogous to genetic proximity at the biological level. Sociobiologists have employed such genetic proximity as the explaining factor of altruism in human and non-human animals, what is known as the "inclusive fitness" hypothesis (Hamilton (1964); Wilson (1975)). The contrast between Smith's theory and the inclusive fitness hypothesis cannot be elaborated here. However, it is sufficient to state that the ideas of social proximity and genetic proximity try to account for the strength or weakness of sympathetic sentiments. Whether sympathetic sentiments are learned reactions through conditioning, or have deep biological foundation, is another issue that is not discussed here.

It is sufficient to note that Smith's theory allows us to conceive altruism as an elastic behavior. It varies with the variation of social proximity; it is not limited by fixed genetic proximity. To account for social proximity, which partially determines the altruistic act, we need an operative morphology of the station of the actor in relation to the recipient's.

\subsection{Sympathy as Station Switching}

As stated above, Smith's principle of sympathy entails continuity between the pursuits of self-interest (what Smith calls the "virtue of prudence") and other-interest (the "virtue of beneficence"). He grounded the commensurability between self- and other-interest on the "self" acting from a separate station-a station that impartially adjudicates between the needs of the self and the needs of the other:

We can never survey our own sentiments and motives... unless we remove ourselves, as it were, from our own natural station and endeavor to view them as at a certain distance from us. ... We endeavor to examine our own conduct as we imagine any other fair and impartial spectator would examine it (Smith (1976) p. 110) (emphasis added).

When I endeavor to examine my own conduct... it is evident that... I divide myself into two persons; and that I, the examiner and the judge, represent a different character from that other $I$, the person whose conduct is examined into the judged of (Smith (1976) p. 113).

For Smith, humans are capable of judging themselves because the principle they use to judge others is readily available :

The principle by which we naturally either approve or disapprove of our own conduct, seems to be altogether the same with that by which we exercise the like judgements concerning the conduct of other people (Smith (1976) p. 107). 
However, there is an irregularity that Smith overlooks. Agents often apply double standards : In many cases, agents tend to do what they would condemn in others. At first examination at least, there is a difference between the agent-as-actor and the agent-as-judge. Agents in many occasions do not switch stations when they judge their own actions as fairly as when they judge the actions of others. Although Smith discusses many other irregularities stemming from the weakness of character, such as false pride and self-aggrandizement (Khalil (1996)), he does not discuss this irregularity explicitly. Smith does discuss similar self-biases, such as self-deception, and reasons that "general rules", or what modern economists call "institutions", arise to correct them. It would be outside the scope of this essay to detail Smith's discussion of the origin of general rules (see Khalil (2000) pp. 381-384). However, following Smith's order of theoretical approximations, it would be consistent to assume, at first level of generality, that agents do not suffer from double standards, and then account for anomalies such as double standards, and corresponding remedies, at second and third levels of generalities. In this light, double standards are not fatal anomalies because they can explain the origin of general rules.

Disregarding double standards, self-judgment, for Smith, is possible because nature has endowed the agent with the quest to be "what he himself approves of other men", and to "dread the very thought of resembling" what he hates and despises in other people (Ibid. p. 117). Thus, when the agent examines the merit of his action, he adopts the view of a would-be impartial spectatoror at least he is supposed to adopt the view of the impartial spectator. It is true that almost all people, at least in a few occasions, fail to do so. But this is a problem for second and third theoretical approximations as just noted.

Smith's theory of sentiments resembles, at the formal level only however, Becker's egocentric approach. It differs from Becker's at the substantive level. To reconstruct Smith's theory, we have at hand the station of the acting self, $S$, the station of the recipient other, $\mathrm{O}$, and the station of the would-be impartial spectator occupied by the self reflecting on itself, coined here "spectator self," $S^{s}$. Figure 1 illustrates such a three-station scenario, where $S^{s}$ examines the utilities of $O$ and $S^{s}$ from a detached, third station whose location is determined by the degree of familiarity. The occupation of the third station of the impartial spectator by the actor himself has two clear implications. First, when the actor empathizes with the suffering of the other, it is not by imagining such suffering as happening to his own person as supposed by Becker's egocentric view. Second, the judge of the potential action is not an actual spectator for two reasons. The first reason is that the judge is not a disinterested observer according to whose opinion agent $S$ tries to conform. In other words, we do not have here a socialization process where $S$ tries to appease the public and gain its applause. Rather, $S$ adopts the view of $S^{s}$ - the impartial spectator who emerges which $S$ examines his own act from a distance. Such a Smithian approach means that, at first approximation, the "self" precedes public opinion or the sociocultural milieu. 


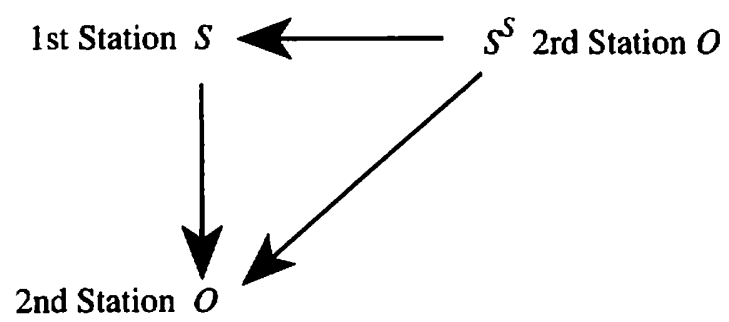

Figure 1: Three-Station Scenario of Altruism

But, for Smith, the milieu is not totally disregarded. It plays a role when it helps the formation of the self by allowing the agent to reflect on his action as he does on the action of others. Without society, the agent cannot take a look at his action from a distance. So, society acts as a reflection mirror that clarifies and intensifies $S$ 's view of himself. For Smith, while society is essential for the development of the self, it does not act as a construction engineer à la Mead.

The second reason is that the judge of the action is not $\mathrm{O}$ as entailed by the Mead/Frank altercentric view. Rather, it is $S^{s}$ who judges, given the degree of familiarity, whether the benefit of $O$ is worth satisfying at the expense of S's interest. This entails that, besides familiarity, one has to introduce the issue of comparative benefit in order to provide a determinate judgment if someone should help a potential beneficiary. It is insufficient that the other is a close associate. The benefactor may prefer to donate funds to a charity that helps abused children than to help a less needy but a closer acquaintance. Smith did not discuss the issue of comparative benefit explicitly. However, Smith succeeded in locating the question of familiarity or sympathy as the proper entry point to the study of altruism.

\subsection{The Advantages of Smith's Theory}

Smith's notion of sympathy is fruitful for several reasons. First, Smith uses the concept "sympathy" in a sense much broader than altruism. He employs it to explain etiquettes, the propriety of emotions in public, the judgement of respect, the expression of admiration, and so on (Khalil (1990), (1996)). Second, Smith's notion of sympathy allows one to commence with the interaction of rational agents-where agents make decisions in light of preferences of the self and cared-about other, constraints, and technology. Smith's notion of sympathy accounts for altruism without appealing to special preferences. In this sense, Smith's notion accords with one major thrust of economic theory, i.e., the stability of preferences : Do not start theorizing at the abstract level by tracing differences in decisions to differences in preferences (Stigler \& Becker (1977)) ranging from God's commandments, social values and commitments, genetic/biological factors, to cultural institutions. The commencement with preferences and variation across cultures begs a bigger 
question : why do preferences differ? In fact, one may use Smith's notion of sympathy to uncover the origin of many cultural institutions and social norms.

Third, Smith's approach locates the explaining variable, sympathy, at the same level as the explained item, the genuine concern about the recipient's welfare. Fourth, Smith's notion allows us to avoid the arbitrary division of agents into the altruist and egoist types (e.g., Becker (1976)). To determine who is the altruist and who is the beneficiary, one does not even need to assume different intensities of sympathetic sentiments or appeal to tastes. The only determinant can be relative incomes or endowments.

Fifth, Smith's notion permits us to use the principle of rationality in the sense of the maximization model of standard economics; i.e., there is no need for the evolutionary Darwinian model or, in specific, the inclusive fitness hypothesis. This is an advantage since the evolutionary model cannot explain easily altruism when there is no genetic proximity. ${ }^{1}$

Sixth, Smith's starting point with sympathy highlights the importance of social proximity (Smith (1976) pp. 219-221). Familiarity provides the operative morphology of the station of the actor in relation to the station of the potential beneficiary. To quote Smith on the importance of familiarity, as much as a man of humanity in Europe sympathizes with the victims of a calamity in China, he is, "provided he never saw them", more stressed for losing his little finger :

Let us suppose that the great empire of China, with all its myriads of inhabitants, was suddenly swallowed up by an earthquake, and let us consider how a man of humanity in Europe, who had no sort of connexion with that part of the world, would be affected upon receiving intelligence of this dreadful calamity. He would, I imagine, first of all, express very strongly his sorrow for the misfortune of that unhappy people, he would make many melancholy reflections upon the precariousness of human life, and the vanity of all the labours of man, which could thus be annihilated in a moment. ... And when all this fine philosophy was over, when all these humane sentiments had been once fairly expressed, he would pursue his business or his pleasure, take his repose or his diversion, with the same ease and tranquillity, as if no such accident had happened. The most frivolous disaster which could befal himself would occasion a more real disturbance. If he was to lose his little finger to-morrow, he would not sleep to-night; but, provided he never saw them, he will snore with the most profound security over the ruin of a hundred millions of his brethren, and the destruction of that immense multitude seems plainly an object less interesting to him, than this paltry misfortune of his own (Smith (1976) pp. 136-137). ${ }^{2}$

1 The suggestion that evolutionary theory is somewhat irrelevant goes against the work of Frank (1988), Margolis (1982), Simon (1990), Bergstrom (1995), Getty (1989), and many others who try to trace altruism to some genetic foundation. Even if sympathy has some biological foundation, one cannot explain the variety of choices by appealing to genes. Also, if sympathy has a biological foundation, it does not mean it is the product of natural selection. In fact, natural selection cannot explain the origin of sympathy; it can only explain its diffusion given that it exists. The inclination to invoke natural selection as soon as one appeals to the relevance of biology with respect to behavior probably stems from the misidentification of organization (physiology) with evolutionary diffusion (evolutionary biology) (see passim Boyd \& Noble, (1993); Rosen, (1991): Khalil, (1999)). 
Seventh, Smith's notion of sympathy allows us to model self- and other-interest (what he calls the virtues of "prudence" and "beneficence") as lying along a continuum. In this regard, Smith's conception is congruent, as suggested earlier, with the modern egocentric view, where altruism is regarded as a motive in the utility function that is smoothly substitutable with self-interested motives.

\section{Smith's Critique of Three Theories of Altruism of His Time}

Although he referred to them by different names, Smith explicitly and emphatically censured what is called here Axelrod's egoistic, Becker's egocentric, and Mead/Frank's altercentric theories of altruism. With regard to the egoistic approach, which stresses self-interest as almost the sole motive, Smith castigated its representative of his day, viz., Bernard Mandeville. Smith ((1976) pp. 308-313) pointed out that Mandeville's view couldn't even distinguish selfishness from legitimate self-interest or what Smith called the "virtue of prudence." While Mandeville equated self-interest with vice. Smith regarded the pursuit of self-interest as a legitimate, moral task entrusted by "Nature" in us: "The preservation and healthful state of the body seem to be the objects which Nature first recommends to the care of every individual" (Ibid., p. 212).

Moreover, Smith chided the exemplary of the egocentric explanation of his time, viz., Thomas Hobbes, which self-centric, vicarious pleasure as the sole motive. Although Hobbes did not develop fully his theory of political psychology, it entailed that the act of altruism is aimed at enhancing the donor's utility by imagining the conditions of the recipient as happening to the donor's own station. A famous vignette told by John Aubrey illustrates Hobbes' view :

One time, I remember, goeing in the Strand, a poor and infirme old man craved his (Hobbes') almes. He, beholding him with eies of pitty and compassion, putt his hand in his pocket, and gave him 6d. Sayd a divine (scil. Dr. Jaspar Mayne) that stood by-'Would you have donne this, if it had not been Christ's command?'-'Yea', sayd he.-'Why?' quoth the other.'Because', sayd he, 'I was in paine to consider the miserable condition of the old man; and now my almes, giving him some reliefe, doth also ease me' (Aubrey (1898) p. 352).

That is, the reason behind the donation is the alleviation of the donor's discomfort at the sight of a beggar. The improvement of the beggar's income is the donor's attempt to enhance his vicarious pleasure. In response to Hobbes' egocentricism, Smith stressed that the sympathetic act involves putting one's self in the other's station rather than judging the other's pleasure from one's own station. Sympathy would be a "selfish sympathy" 
if it entails imagining the other's conditions as happening to one's station, i.e., one's "own person and character" :

Sympathy ... cannot, in any sense, be regarded as a selfish principle. When I sympathize with your sorrow or your indignation, it may be pretended, indeed, that my emotion is founded in self-love, because it arises from bringing your case home to myself, from putting myself in your situation, and hence conceiving what I should feel in the like circumstances. But though sympathy is very properly said to arise from imaginary change of situations with the person principally concerned, yet this imaginary change is not supposed to happen to me in my own person and character, but in that of the person with whom I sympathize. When I condole with you for the loss of your son, in order to enter into your grief I do not consider what $I$, a person of such character and profession, should suffer, if I had a son, and if that son was unfortunately to die : but I consider what I should suffer if I was really you, and I not only change circumstances with you, but I change persons and characters. My grief, therefore, is entirely upon your account, and not in the least upon my own. It is not, therefore, in the least selfish. How can that be regarded as a selfish passion, which does not arise even from the imagination of any thing that has befallen, or that relates to myself, in my own proper person and character, but which is entirely occupied about what relates to you? A man may sympathize with a woman in child-bed; though it is impossible that he should conceive himself as suffering her pains in his own proper person and character (Smith (1976) p. 317).

In addition, Smith attacked the altercentric position of his age, which appeals to moral dictums, as expressed in the moral philosophy of Francis Hutcheson and other figures of the Scottish Enlightenment. Smith considered them as leftovers from the medieval philosophy of the Christian church. Smith ((1976) pp. 139-140, 300-304) distanced himself from the "whining and melancholy moralists" such as Hutcheson who identified virtue exclusively with altruism. ${ }^{3}$ This identification implies that self-interest is basically selfish and amoral-a position which is ironically, as Smith notes, similar to Mandeville's-while virtue is basically about the adoption of the interest of others or the community at large. For such an altercentric view, there is little room left for self-interest. The negation of self-interest occurs when the self transports itself totally from its station to the station of others. This means that one adopts the needs of others while dismisses one's own needs and wants as illegitimate, immoral, and selfish.

Such an altercentric stand implies that altruism stems from strict moral dictums not different from honesty or obligatory commitment in general. Smith ((1976) pp. 78-82) explicitly criticized such an implication when he distinguished between sympathy, the origin of altruism or what he called "beneficence", and honesty, which stems from what he called "justice".4

3 Such identification is to some extent echoed in recent philosophical literature. For example, Sagoft (1986) opposes "self-interest" and "public values" on the basis that the later are reflective. Likewise, Postema (1987) contrasts "personal values" and "collective values." Goodin (1980) argues that cost-benefit calculations should be totally differentiated from ethical considerations. Likewise, Walzer (1983) distinguishes ethical tastes (what he calls "obligations") on the basis of being "sacred" from economic sphere of efficient rationality.

4

Therefore, it is surprising that Geoffrey Brennan and Lomasky (1985) appeal to Smith's concept of sympathy to argue that voting behavior is best understood as stemming from obligatory commitment rather than from 
The conflation of the two is the core of the conception of altruism as subject to rules not different from the rules of justice. Smith ((1976) part VII) dedicated the last part of The Theory of Moral Sentiments to the critique of medieval moral philosophers, whom he called the "casuists", for treating voluntary action such as altruism as subject to strict rules of justice. Casuists acted as prigs or pedants, according to Smith. They failed to observe the arena of beneficence as separate from obligatory commitments. For Smith ((1976) pp. 78-82), beneficence, unlike justice or rules against cheating, is similar to prudence and, hence, is subject to evaluation in light of circumstances.

\section{The Modern Reincarnation of the Three Theories}

Insofar as sympathy is the spring of altruism, it allows agents to act not according to strategic calculation but rather according to the concern over the welfare of others-contrary to the egoistic view. It also allows agents to act not out of self-indulgence in vicariously experiencing the pleasure of others but rather out of genuine concern-contrary to the egocentric approach. In addition, it allows agents to act not according to obligatory behavior but rather out of familiarly and relative circumstances-contrary to the altercentric view.

Smith's view challenges the three approaches represented by Axelrod, Becker, and Mead/Etzioni/Frank/Simon in the same ways Smith confronted their parallel representations of his time. Concerning the modern egoistic perspective, epitomized by Axelrod's "tit-for-tat" strategy, it was not designed originally to explain altruism, but rather to explain cooperative behavior with regard to non-cheating strategies. Insofar as cooperative behavior is not confused with altruism, Axelrod's egoistic approach has many insights to learn from. However, insofar as altruism appears to be a nonselfish act, as evidentially the case in single-spot encounters, the egoistic approach is problematic if it extends itself to explain such altruistic acts.

By extending itself to the phenomenon of altruism, the egoistic approach maintains that agents assist others strategically, i.e., to induce them to reciprocate favors. That is, all actions are motivated ultimately by selfinterest. As such, it suffers from the same shortcoming that Smith found in Mandeville's approach. It cannot differentiate between selfishness and legitimate self-interest.

Concerning Becker's egocentric perspective, it maintains that benefactors increase their utility by imagining how recipients are enjoying the

self-interest. While voting behavior may stem from obligatory commitment, Smith's principle of sympathy cannot account for such a commitment. While Smith did not discuss explicitly obligatory commitment, it might be derived from his discussion of the virtue of justice that he explicitly distanced from sympathy (Khaill (1998)). 
donated goods. This egocentric explanation can account for single-spot transactions, where the egoistic approach fails. In fact, the egocentric explanation, as mentioned earlier, resembles, formally, Smith's explanation. However, the egocentric explanation basically cannot distinguish benefactors from masochists who endure disutility when they donate resources in the hope of attaining an offsetting level of arousal. In other words; the masochist, similar to any rational agent, suffers from pain (disutility) when he donates resources. But he expects to be compensated by a greater vicarious pleasure, experienced from his own station, when he watches the pleasure of the recipient. Becker's model entails that altruists should feel joyful over the prospect of the miseries of others because such miseries occasion for them the opportunity to be aroused. In fact, Becker recognizes this strange implication, noted earlier by Hobbes, when he approvingly quotes the statement made by a beneficiary to his benefactors in Charles Dickens's Bleak House :

It's only you, the generous creatures, whom I envy. ... I envy you your power of doing what you do. It is what I should revel in, myself. I don't feel any vulgar gratitude to you. I almost feel as if you ought to be grateful to me, for giving you the opportunity of enjoying the luxury of generosity. ... I may have come into the world expressly for the purpose of increasing your stock of happiness. I may have been born to be a benefactor to you by sometimes giving you an opportunity of assisting me in my little perplexities (cited by Becker (1981) p. 13, n. 2).

The inability to distinguish the masochist from the altruist is a direct outcome of the way Becker models charity or caring, which Smith has found deficient in Hobbes' theory. Sure enough, there are many acts of resource sharing that are motivated by self-centered indulgences that agents seek to satisfy. However, hardly any thinker would not be disturbed by the prospect of identifying all acts of altruism as merely variants of masochism.

Concerning Mead/Frank's altercentric view, it avoids the failings of the egoistic and the egocentric perspectives: The altercentric view can account for resource-sharing where the agent is involved in single-spot transactions and does not stand to extract vicarious satisfaction. This is possible because the altercentric view regards altruism as stemming from moral dictums and, hence, can account for single-spot transfers stemming out of genuine concerns. However, the altercentric view implies that altruism does not differ from strict rules of justice - such as obligatory commitments not to cheat or violate the property rights of others. To be accurate, it might be the case that many instances of resource-sharing stem from fairness and the desire not to appear as a "free-rider." This desire explains volunteering to support the local fire department, complying with pollution-control customary rules, or supporting commonly shared resources. However, there is a domain of resource sharing that does not arise from obligatory commitment. Insofar as the altercentric approach over-extends itself to explain altruism, it raises some questions.

For instance, the critical factor in altruism is sympathy, which plays a little role in the altercentric view. Smith's principle of sympathy signifies 


\begin{tabular}{|c|c|c|c|}
\hline Egoism & Egocentricism & Altercentricism & Altruism \\
\hline Resource & Resource & Resource & Resource \\
sharing & sharing & sharing & sharing \\
ensures & captures & expresses & acts on \\
cooperative & self-centered & canons & sympathetic \\
responses & sentiments & of morality & sentiments \\
\hline
\end{tabular}

Figure 2 : Domains of Resource-Sharing

that the concern over other-interest arises from particular station switching and, hence, voluntary, while moral dictums (or "moral gene" according to biological versions of the altercentric view (Frank (1988))) dictate action with usually little regard to the particular circumstances or persons involved. If one advances the principle of sympathy to explain voluntary acts of altruism à la Smith, one would spare himself the need to introduce the question of commitment via Sen ((1977), (1985); cf. Khalil (1999)) and Frankfurt (1971). In fact, one would not need to invoke the multiple-self framework à la Etzioni ((1986); see Sen, (1980/1981)) as well. Put differently, as Smith noted in his critique of Hucheson, there are many acts of resource sharing which do not fall under strict rules of justice. Such acts are rather nonobligatory and contingent on particular circumstances.

\section{Conclusion}

Monroe ((1994), (1996), chs. 6-9) reviews different theories of altruism along disciplinary lines separating sociology, economics, biology, and psychology. In comparison, this paper proves that what matters is the conceptual core, which transcends the somewhat artificial divisions among disciplines and even linguistic and intellectual apparatuses separated by centuries.

The paper finds three major theories of altruism that cut across the social sciences and intellectual milieus : the egoistic, egocentric, and altercentric perspectives. The paper argues that neither Axelrod's egoistic view, Becker's egocentric approach, nor Mead/Frank's altercentric perspective covers altruistic resource sharing as understood by Smith. The received three theories are rather about strategic, masochist, or obligatory resource sharing. As summarized in Figure 1, the three modern theories do not explain altruism as stemming from genuine sentiments about the welfare of others. The egoistic approach explains instead reciprocity as a strategic act to enhance future benefit in infinitely repeated games. The egocentric view regards resource-sharing as no different from a utility-arousing masochist act : the actor inflicts pain on himself (donates resources) to allow his own person - i.e., without switching stations - to experience enjoyment via the stimulus of watching the recipient's pleasure. The altercentric agenda is actually 
about fixed canons and, hence, cannot express the voluntary and varied character of altruism. Insofar as altruism is a non-strategic, non-masochistic, and non-obligatory action, these theories are generally deficient at first approximation.

Smith's theory of sympathy offers a better starting point to understand non-strategic, non-masochist, and non-obligatory transfers of resources. Rather than starting with the egoist, ego-centered, or alter-centered agent, Smith commences with a normal agent who is capable of true sympathy in the sense that he can distance himself from his own station, but without totally disregarding his own self-interest. Such an agent may share his resources with others even in single-spot transactions, which the egoist would not. Such an agent may "empathize" with others by transferring himself to their station, which the ego-centered would not. And such an agent may make his grant contingent on his sympathy and cost-benefit calculation, which the alter-centered prig would not.

Put in simple terms, Smith's approach shows that the altruistic sense of resource sharing is neither made from the first station of the actor, as maintained by the egoistic and egocentric approaches, nor from the second station of the recipient, as postulated by the altercentric approach. Rather, following Smith, the decision maker is situated externally to the actor and the recipient, viz., in an imagined third station. For the theorist to determine the extent of assistance, the theorist needs to specify the extent of familiarity. Moreover, the theorist needs to specify the benefactor's loss relative to the beneficiary's valuation of the assistance.

Although Smith did not discuss the question of comparative utility, he brought to our attention the centrality of station switching and judging from a distance (i.e., sympathy) for the understanding of altruism. One implication is that human society is not held together solely on the ground of self-interested and self-indulging passions. Also, for human society to subsist, there is no need for an authority empowered by an external system of ethics. Human fraternity arises from the every-day interaction of agents that nurtures familiarity. What is unique about Smith's approach is that the principle, which originates fraternity, i.e., sympathy, is the same one that makes the agent interested in promoting his own self-interest. In his critique of Mandeville, Smith was explicit that the pursuit of self-interest is not vice but rather a virtue. 


\section{References}

Aubrey, J. (1898), Brief Lives, chiefly of contemporaries, set down by John Aubrey, between the Years 1669 \& 1696, vol. 1 (A-H), ed. Andrew Clark, Oxford, Clarendon Press.

Axelrod, R. (1984), The Evolution of Cooperation, New York, Basic Books.

Becker, G.S. (1976), "Altruism, Egoism, and Genetic Fitness : Economics and Sociobiology", Journal of Economic Literature, 4, pp. 817-26. (Reprinted in Zamagni, 1995.)

Becker, G.S. (1981), "Altruism in the Family and Selfishness in the Market Place", Economica, 48, pp. 1-15. (Reprinted in Zamagni, 1995.)

Bergstrom, T.C. (1995), "On the Evolution of Altruistic Ethical Rules for Siblings", American Economic Review, 85, pp. 58-81.

Boyd, C.A.R. and D. Noble (eds) (1993), The Logic of Life : The Challenge of Integrative Physiology, Oxford, Oxford University Press.

Brennan, G. and L. Lomasky (1985), "The Impartial Spectator Goes to Washington : Toward a Smithian Theory of Electoral Behavior", Economics and Philosophy, 1, pp. 189-211.

Collard, D. (1978), Altruism and Economy: A Study in Non-Selfish Economics, Oxford, Martin Robertson.

Etzioni, A. (1986), "The Case for a Multiple-Utility Conception", Economics and Philosophy, 2, pp. 159-183.

Frank, R.H. (1988), Passions Within Reason: The Strategic Role of the Emotions, New York, W.W. Norton.

Frankfurt, H.M. (1971), "Freedom of the Will and the Concept of a Person", Philosophical Review, 68, pp. 5-20.

Getty, G. (1989), "The Hunt for r : One-Factor and Transfer Theories", Social Science Information, 28, pp. 385-428.

Goodin, R.E. (1980), "Making Moral Incentives Pay", Policy Sciences, 12, pp. 131-145.

Haakonssen, K. (1981), The Science of a Legislator : The Natural Jurisprudence of David Human and Adam Smith, Cambridge University Press.

Hamilton, W.D. (1964), "The Genetical Evolution of Social Behavior", I, II, Journal of Theoretical Biology, 7, pp. 1-16, 17-52.

Khalil, E.L. (1990), "Beyond Self-Interest and Altruism : A Reconstruction of Adam Smith's Theory of Human Conduct", Economics and Philosophy, 6, pp. 255-273. (Reprinted in Zamagni, 1995.)

Khalil, E.L. (1996), "Respect, Admiration, Aggrandizement : Adam Smith as Economic Psychologist", Journal of Economic Psychology, 17, pp. 555-577.

Khalil, E.L. (1998), "Is Justice the Primary Feature of the State? Adam Smith's Critique of Social Contract Theory", European Journal of Law and Economics, 6, pp. 215-230. 
Khalil, E.L. (1999), "Sentimental Fools : A Critique of Amartya Sen's Notion of Commitment", Journal of Economic Behavior and Organization, 40, pp. 373-386.

(URL : www.sciencedirect.com/science/journal/01672681)

Khalil, E.L. (2000), "Beyond Natural Selection and Divine Intervention: The Lamarckian Implication of Adam Smith's Invisible Hand", Journal of Evolutionary Economics, 10, pp. 373-393.

Mackie, J. (1980), Hume's Moral Theory, London, Routledge \& Kegan Paul. Margolis, H. (1982), Selfishness, Altruism and Rationality: A Theory of Social Choice, Cambridge University Press.

Mead, G.H. (1934), Mind, Self and Society, edited by C.W. Morris, Chicago, University of Chicago Press.

Monroe, K.R. (1994), "A Fat Lady in A Corset : Altruism in Social Theory", American Journal of Political Science, 38, pp. 861-893.

Monroe, K.R. (1996), The Heart of Altruism: Perceptions of a Common Humanity, Princeton, NJ, Princeton University Press.

Postema, G.J. (1987), "Collective Evils, Harms, and the Law" Ethics, 97, pp. 414-440.

Rosen, R. (1991), Life Itself: A Comprehensive Inquiry into the Nature, Origin, and Fabrication of Life, New York, Columbia University Press.

Sagoff, M. (1986), "Values and Preferences", Ethics, 96, pp. 301-316.

Sen, A.K. (1977), "Rational Fools : A Critique of the Behavioral Foundations of Economic Theory", Philosophy \& Public Affairs, 6, pp. 317-344.

Sen, A.K. (1980/1981), "Plural Utility", Proceedings of the Aristotelian Society, 80, pp. 193-215.

Sen, A.K. (1985), "Goals, Commitment, and Identity", Journal of Law, Economics and Organization, 1, pp. 341-355. (Reprinted in Zamagni, 1995.)

Simon, H.A. (1990), "A Mechanism for Social Selection and Successful Altruism", Science, 250, pp. 1665-1668. (Reprinted in Zamagni, 1995.)

Smith, A. (1976), The Theory of Moral Sentiments, edited by D.D. Raphael \& A.L. Macfie, Oxford, Clarendon Press.

Walzer, M. (1983), Spheres of Justice: A Defense of Pluralism and Equality, New York, Basic Books.

Wilson, E.O. (1975), Sociobiology: The New Synthesis, Cambridge, MA, Harvard University Press.

Zamagni, S. (ed.) (1995), The Economics of Altruism, Aldershot, UK, Edward Elgar. 
